\begin{abstract}
Management of commercially important crab and shrimp species in Alaska has been hindered by the inability to directly determine the age of individual animals. We investigated the applicability of a recently developed method of age determination to red king crab (Paralithodes camtschaticus), southern Tanner crab (Chionoecetes bairdi), and spot shrimp (Pandalus platyceros) from Alaska. The cuticle structures of the mesocardiac ossicles of crabs and the eyestalks of spot shrimp were visualized with histological staining to identify the endocuticle, where growth bands have been observed in other crustaceans. For all species, paired light and dark bands were observed in longitudinal, thin sections of these structures in the majority of specimens examined. The proximal portion of the mesocardiac ossicle, where growth bands were observed, was absent in the foregut exuviae of red king and southern Tanner crabs that molted in captivity. If validated, counts of growth bands hold promise as a reliable measure for determining age of these species.
\end{abstract}

\title{
Preliminary assessment of a direct age- determination method for 3 commercially important crustaceans from Alaska
}

\author{
Raouf Kilada (contact author) ${ }^{1,2}$ \\ Joel B. Webb ${ }^{3}$ \\ Kevin W. McNeel ${ }^{4}$ \\ Laura M. Slater 5 \\ Quinn Smith6 \\ Jayde Ferguson ${ }^{7}$
}

Email address for contact author: rwkilada@gmail.com

\author{
1 Department of Biology \\ University of New Brunswick (Saint John) \\ 100 Tucker Park Road \\ Saint John, New Brunswick E2L 4L5, Canada \\ 2 Department of Marine Science \\ Suez Canal University \\ Ismailia 41522, Egypt \\ 3 Division of Commercial Fisheries \\ Alaska Department of Fish and Game \\ P.O. Box 115526 \\ Juneau, Alaska 99811-5526 \\ ${ }^{4}$ Age Development Unit, Mark, Tag, and \\ Age Laboratory \\ Alaska Department of Fish and Game \\ P.O. Box 115526 \\ Juneau, Alaska 99811-5526
}

\author{
${ }^{5}$ Division of Commercial Fisheries \\ Alaska Department of Fish and Game \\ 351 Research Court \\ Kodiak, Alaska 99615 \\ ${ }^{6}$ Division of Commercial Fisheries \\ Alaska Department of Fish and Game \\ P.O. Box 110024 \\ Juneau, Alaska 99811-0024 \\ 7 Pathology Laboratory \\ Alaska Department of Fish and Game \\ 333 Raspberry Road \\ Anchorage, Alaska 99518-1599
}

Manuscript submitted 10 August 2015. Manuscript accepted 25 October 2016. Fish. Bull. 115:42-49 (2017).

Online publication date: 15 November 2016. doi: 10.7755/FB.115.1.4

The views and opinions expressed or implied in this article are those of the author (or authors) and do not necessarily reflect the position of the National Marine Fisheries Service, NOAA.
For many fish and invertebrate species, age can be determined directly from growth bands recorded in calcified hard structures. These structures include bones, scales, and otoliths in fish species (Campana, 2001) and statoliths and shell sections in a variety of invertebrates (Jensen, 1969; Kilada et al., 2007; Abele et al., 2009). Similar methods have not been applied to decapod crustaceans because of the presumed loss and replacement of calcified structures during ecdysis (Vogt, 2012). Instead, indirect methods, including captive observations, tag-recapture experiments, accumulation of lipofuscin in neural tissue, and analysis of size-frequency dis- tributions, have been applied to infer age (Hartnoll, 2001; Vogt, 2012; Pinchuk et al., 2016).

A lack of reliable age information impedes assessment and management of crustacean fisheries (Caddy, 1986). In Alaska, some major crab stocks are assessed and managed by using length-based population models (e.g., Zheng et al., 1995), in which data on abundance, harvest, growth, and mortality are integrated. However, the accuracy of these models may be compromised if the growth or mortality rates are not truly representative of processes in situ. In contrast, age-structured models implicitly account for variability in growth and mortality by incorporating compre- 


\section{Table 1}

Collection location, date, sex, and number of individual red king crab (Paralithodes camtschaticus), southern Tanner crab (Chionoecetes bairdi), and spot shrimp (Pandalus platyceros) collected in Alaska during 2013-2014 for investigation of presence of growth bands in thin sections of the mesocardiac ossicle of the gastric mill of red king and southern Tanner crabs and in eyestalks of spot shrimp.

\begin{tabular}{|c|c|c|c|c|}
\hline Species & Collection location & Collection date & Sex & $n$ \\
\hline Red king crab & Bristol Bay, Alaska & June 2013 & Female & 30 \\
\hline Southern Tanner crab & Marmot Bay, Kodiak, Alaska & June 2014 & Male & 34 \\
\hline Spot shrimp & Seymour Canal, southeast Alaska & February and June 2014 & Male and female & 30 \\
\hline
\end{tabular}

hensive size- and abundance-at-age data (Quinn and Deriso, 1999).

A direct method for determining age based on counting bands in the endocuticle layer has been presented for decapod crustaceans (Leland et al., 2011; Kilada et al., 2012). Bands were initially described in the ossicles of the gastric mill for 6 species (Leland et al., 2011; Kilada et al., 2012) and in the eyestalks of 2 additional species (Kilada et al., 2012). These observations have since been extended to additional crab, lobster, and shrimp species and to euphausids (Kilada and Acuna, 2015; Kilada et al., 2015; Sheridan et al., 2015; Kilada and Ibrahim, 2016; Krafft et al., 2016) and have been further supported by technical development, corroboration, and validation (Sheridan et al., 2015; Leland et al., 2015).

Our objective was to evaluate the potential of this method for 3 commercially important species in Alaska: the red king crab (Paralithodes camtschaticus), southern Tanner crab (Chionoecetes bairdi), and spot shrimp (Pandalus platyceros). Feasibility was evaluated 1) by identifying the endocuticle layer by histological examination, 2) by observing the presence or absence of growth bands in the endocuticle of the mesocardiac ossicles of crabs and eyestalks of shrimp, and 3) by determining whether the region of the mesocardiac ossicle, where growth bands have been observed, may be retained during ecdysis for these crab species. The mesocardiac ossicle was selected as the primary structure for investigation in the 2 crab species because of the presence of clear bands and evidence of possible retention through ecdysis (Leland et al. 2011; Kilada et al., 2012). The eyestalks of shrimp were selected because of the dissimilarity between crab and shrimp gastric mill ossicles and because of the evidence of the presence of bands in the eyestalk of shrimp (Kilada et al., 2012).

\section{Materials and methods}

\section{Histological examination}

Red king crab and spot shrimp were collected in southeast Alaska in 2014, by using pot gear, and southern Tanner crab were collected near Kodiak, Alaska, in 2014 by using trawl gear ( $n=3$ for each species). Gastric mills of red king and southern Tanner crabs and paired eyestalks of spot shrimp were dissected and preserved in Bouin's fixative for approximately 1 month and then transported to the Fish Pathology Laboratory of the Alaska Department of Fish and Game in Anchorage, Alaska. Before processing, mesocardiac ossicles of some red king crabs were trimmed to fit within histological cassettes $\left(1 \mathrm{~cm}^{2}\right)$, but most ossicles and eyestalks did not require trimming. Structures were transferred to $70 \%$ ethanol and decalcified with Evans and Krajian fluid (Evans and Krajian, 1930). Tissues were dehydrated, infiltrated, and embedded in paraffin with an automatic tissue processor. Histological cassettes were cut longitudinally into 6 - $\mu \mathrm{m}$ sections with a rotary microtome, and sections were mounted onto glass slides. Sections of mesocardiac ossicles of crabs and eyestalks of spot shrimp were prepared and stained with Masson's trichrome (Thermo Fisher Scientific ${ }^{1}$, Waltham, MA) and permanently mounted with Permount mounting medium (Thermo Fisher Scientific). Masson's trichrome was expected to stain the endocuticle and exocuticle layers blue and the membranous layer (hypodermis) and epicuticle red. The cuticle layers (for detailed description, see Vatcher et al., 2015) were then examined with a Zeiss microscope (Carl Zeiss Microscopy, Jena, Germany) and photographed with a Jenoptik digital camera and ProgRes CapturePro software (JENOPTIK Optical Systems Inc., Jupiter, FL).

\section{Presence of growth bands}

Red king crab, southern Tanner crab, and spot shrimp ( $n=30,34$, and 30 , respectively) of a range of body sizes were collected across Alaska in 2013 and 2014 (Table 1). Carapace length (CL) and shell condition of red king crabs, carapace width $(\mathrm{CW})$ and shell condition of southern Tanner crabs, CL of spot shrimp, and sex (identified from pleopod morphological features for shrimp) of all specimens were record-

\footnotetext{
${ }^{1}$ Mention of trade names or commercial companies is for identification purposes only and does not imply endorsement by the National Marine Fisheries Service, NOAA.
} 

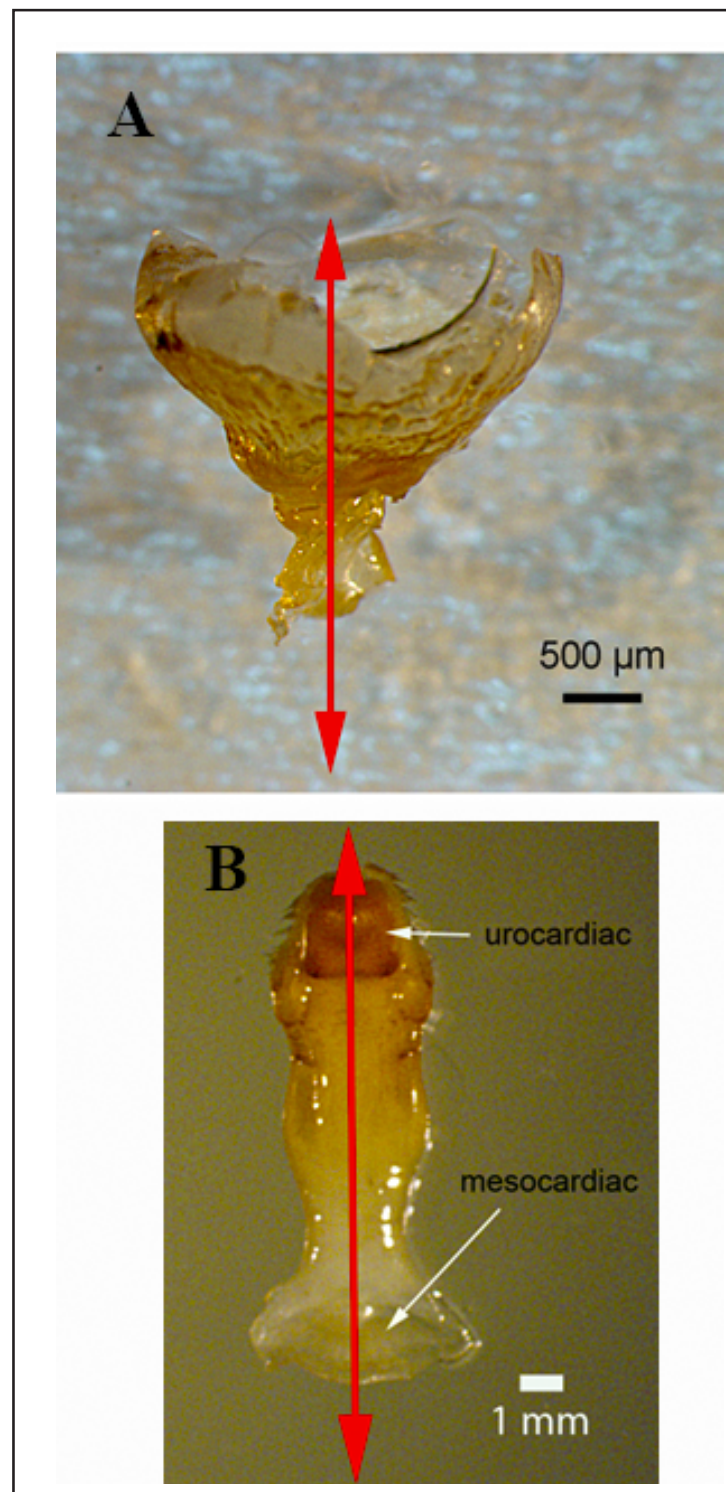

Figure 1

Locations of the longitudinal axes used for preparation of thin sections indicated by red arrows for (A) the eyestalk of spot shrimp (Pandalus platyceros) and (B) the dorsal ossicle (urocardiac and mesocardiac) of red king (Paralithodes camtschaticus) and southern Tanner (Chionoecetes bairdi) crabs, as illustrated with the ossicle of a southern Tanner crab. Red king and southern Tanner crabs and spot shrimp were collected in Alaska during 2013-2014 for this study of a direct age-determination method.

ed at the time of collection. Shell condition, a subjective index of epibionts and wear on the exoskeleton, was noted because it has proven useful for evaluating differences in the recency of molting in crab species (Jadamec et al., 1999; Donaldson and Byersdorfer, 2002). Crab gastric mills and shrimp eyestalks were dissected, cleaned, and preserved in a mixture of ethanol, glycerol, and distilled water (with a volume ratio of $70: 4: 26$ ).

Structures were embedded in cold cure epoxy resin and sectioned longitudinally (Fig. 1) with a diamondbladed IsoMet Low Speed Saw (Buehler, Lake Bluff, IL) at the University of New Brunswick in Saint John, New Brunswick, Canada. Several serial sections (with thickness of 160-180 $\mu \mathrm{m}$ ) were prepared per structure and mounted with epoxy individually on slides, polished by hand with dry, 0.3-pm-grit lapping film, covered with $90 \%$ ethyl alcohol, and viewed under transmitted light with a CX41 Olympus compound microscope (Olympus Corp., Tokyo) at 100-400× magnification. All cuticular layers were examined throughout the thin sections, and bands were recognized as alternating (bipartite) translucent and opaque zones in the endocuticle of crab mesocardiac ossicles and shrimp eyestalks. Photographs were taken with a DP72 Olympus digital camera (Olympus Corp.) attached to the microscope.

\section{Examination of exuvial gastric structures}

Two female red king crab were captured by divers in southeast Alaska and 3 male southern Tanner crab were captured by pot and trawl gear near Kodiak, Alaska, in 2014. Female red king crabs were immature and grasped by males in situ (precopulatory guarding of mate), indicating that the pubertal molt to maturity was imminent. All crabs were held in aquaria with flow-through seawater at ambient seawater temperature and monitored daily until they molted. After ecdysis, the exuvial gastric mill structures were removed and photographed. At 1 week after the molt, the whole stomach was dissected from the crab, and the gastric mill structures were photographed for comparison with the same structures from the exuviae.

\section{Results}

\section{Histological examination of the cuticle}

The endocuticular layer was visually differentiated from other cuticular layers in the mesocardiac ossicles of red king and southern Tanner crabs (Fig. 2) and in the eyestalks of spot shrimp (Fig. 3) after ossicles were stained with Masson's trichrome. The epicuticle, exocuticle, and membranous layers were clearly visible in thin sections of crab mesocardiac, where red indicated the membranous layer and epicuticle (Fig. 2). Lamellar structure, of alternating light and dark stained bands, were more discernible in the mesocardiac of a southern Tanner crab (Fig. 2B) and the exo- and endocuticle of the eyestalk of a spot shrimp (Fig. 3B) than in the mesocardiac of a red king crab (Fig. 2C) at similar magnification. The cuticle layers of the eyestalks of spot shrimp tended to separate during histological sectioning (Fig. 3A). 

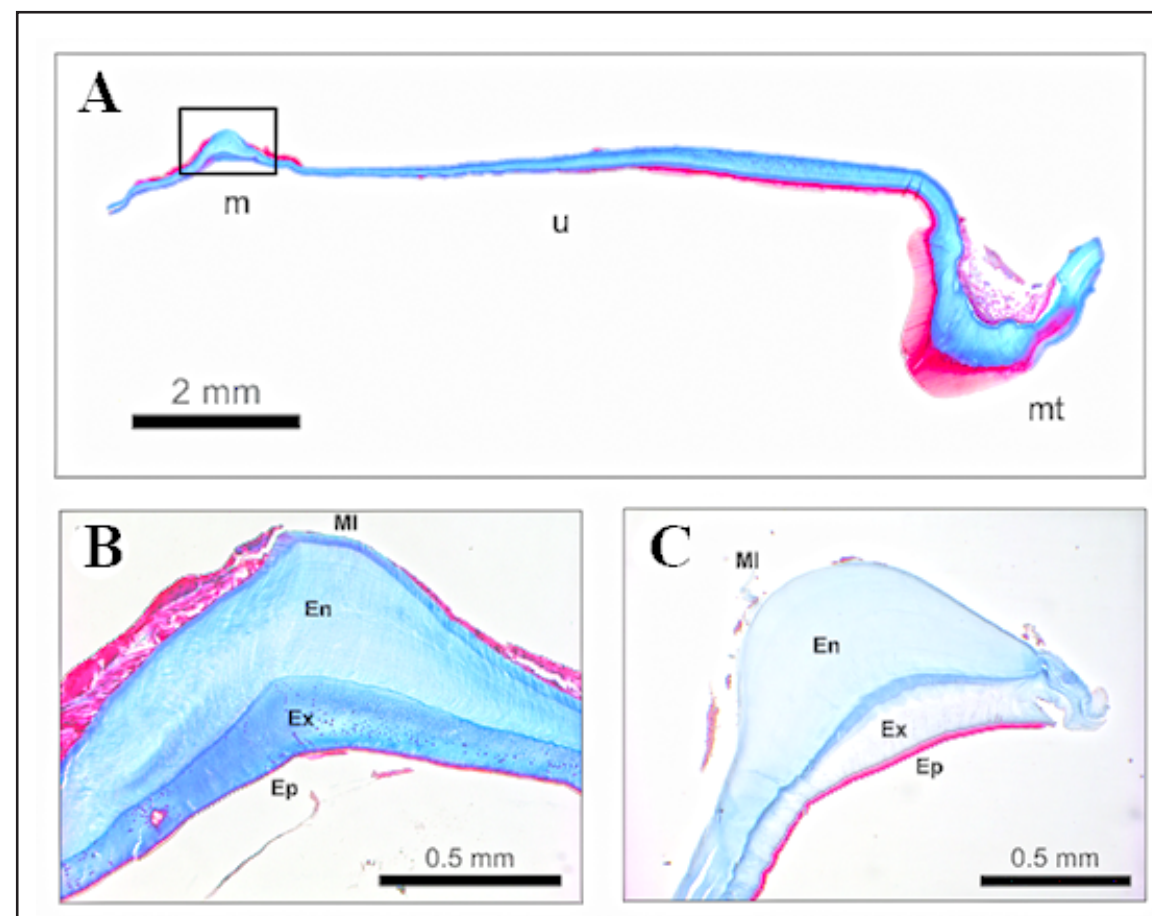

Figure 2

Histological sections (6- $\mathrm{mm}$ thickness), stained with Masson's trichrome, of the (A) dorsal ossicle of a red king crab (Paralithodes camtschaticus) that was collected in southeast Alaska in 2014 and used to represent both the red king crab and the southern Tanner crab (Chionoecetes bairdi). Included are the mesocar$\operatorname{diac}(\mathrm{m})$, the urocardiac $(\mathrm{u})$, and the medial tooth $(\mathrm{mt})$. Higher magnification of the ossicle region denoted by the box in panel A revealed the cuticular layers of the arch of the mesocardiac, as evident in the high-magnification images of 2 other specimens collected in 2014: (B) the southern Tanner crab and (C) the red king crab. The epicuticle (Ep) and membranous layer (Ml) stained red and the exocuticle (Ex) stained a darker shade of blue than the endocuticle (En).

\section{Presence of growth bands}

Thin sections were successfully obtained from the mesocardiac ossicles from 19 red king crabs and 32 southern Tanner crabs and single eyestalks from 18 spot shrimp. For mesocardiac sections of both crab species, bipartite band patterns (exclusive of the lamellae) were clearest in the location of maximum endocuticle thickness in relation to the exo- and epicuticle that was at the proximal end of the structure (Figs. 2A, 4, A-B). For spot shrimp, bands were clearest at the proximal end of the eyestalk with respect to the anterior tip of the cephalothorax (Figs. 3A, 4C).

\section{Ossicular retention throughout ecdysis}

Comparison of gastric mill structures in exuviae with those of postmolt stomachs of crabs indicated differences in presence of regions of the gastric mill. The cusp of the medial tooth of the urocardiac and zygocardiac ossicles of the gastric mill, along with the portion of the ossicle adjacent to each tooth, were the primary structures present in the exuviae of both southern Tanner and red king crabs (Fig. 5A). For both crab species, the anterior portion of mesocardiac, the pterocardiac, and the anterior portions of the zygocardiac ossicles were not visible in the exuviae, but they were present and robust in a postmolt crab, indicating that these portions were potentially retained or resorbed and subsequently replaced (Fig. 5, B and D).

\section{Discussion}

The presence of bands in the endocuticle layer of the mesocardiacs of southern Tanner and red king crabs and in the eyestalks of spot shrimp indicated that determining age on the basis of band counts may be feasible, as it is for other crustacean species (e.g., Leland et al., 2011; Kilada et al., 2012; Leland et al., 2015; Kilada et al., 2015; Sheridan et al., 2015; Kilada and Ibrahim, 2016; Krafft et al., 2016). Histological charac- 

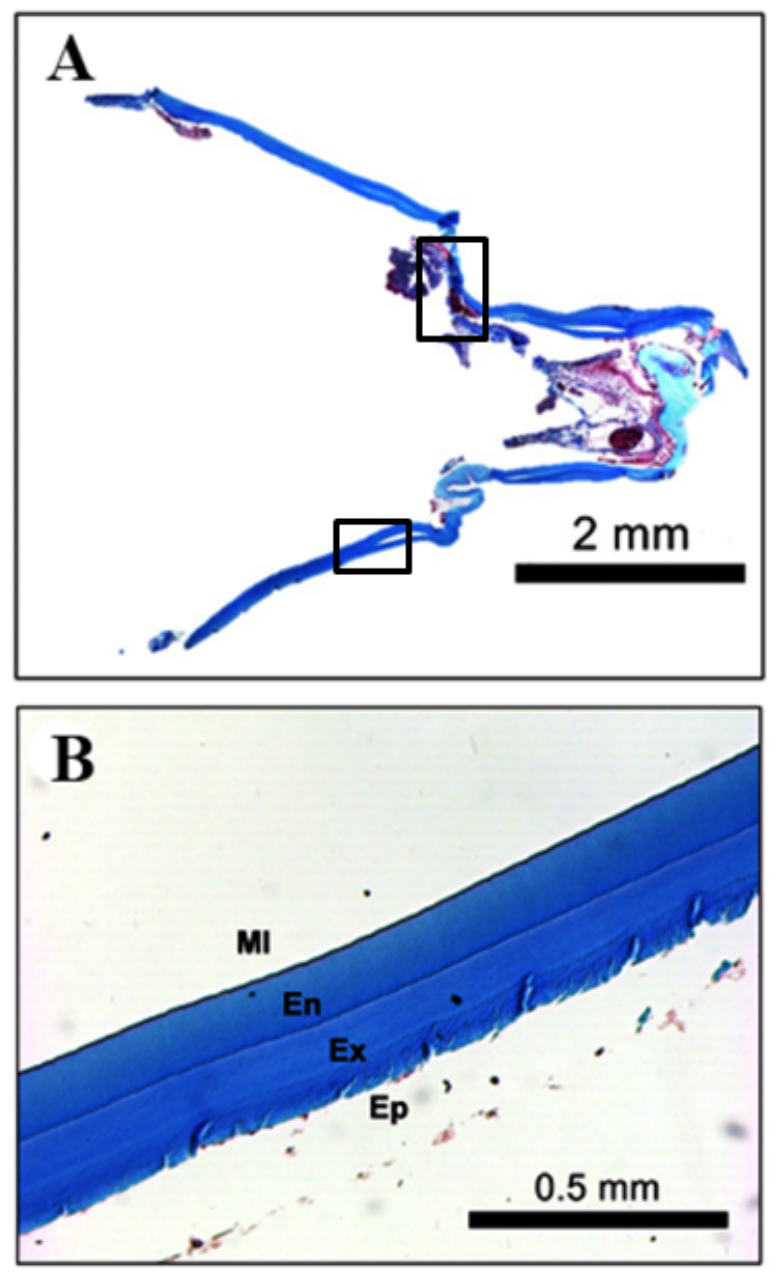

Figure 3

Histological sections (6- $\mu \mathrm{m}$ thickness), stained with Masson's trichrome, of the eyestalk of a spot shrimp (Pandalus platyceros) collected in Alaska in 2014, showing (A) the entire eyestalk and (B) the cuticular layering, as seen in the inset in the smaller, lower small box in panel A, including the epicuticle (Ep), exocuticle (Ex), endocuticle (En), and membranous layer (Ml). The larger box indicates the location within the structure where growth bands were observed in Figure 4C.

terization of the mesocardiac ossicles of the crab species and of the eyestalk of the spot shrimp defined the boundaries between cuticular layers-boundaries that are critical for developing band counting criteria. As with results from studies of other species (e.g., Kilada et al., 2012; Leland et al., 2015), there was preliminary evidence that a portion of the mesocardiac ossicle, where band patterns are observed in the endocuticle, is either retained or replaced during molting. A structure that is retained through ecdysis would be useful for evaluating band information.

The cuticle layers of the mesocardiac ossicles of red king and southern Tanner crabs and the eyestalks of spot shrimp were similar to those observed in other studies of decapod crustaceans (see Roer and Dillaman, 1984, and references therein; Vatcher et al., 2015). Differences in staining results may be due to differences in the specific calcium compound involved in the biomineralization within each region (Vatcher et al., 2015). As in results for blue crab (Callinectes sapidus) with the use of acridine orange (a different histological stain) (Vatcher et al., 2015), the medial tooth of the urocardiac stained similarly and was continuously connected to the epicuticle in both crab species examined in this study (Fig. 2A). This result further supports the hypothesis that the hardened cusp of the tooth is of epicuticular rather than exocuticular origin (Vatcher et al., 2015).

Bipartite patterns were readily visible in the mesocardiac ossicles of red king and southern Tanner crabs and in the eyestalks of spot shrimp. Recurrence of this pattern in multiple individuals indicates that band counts may be promising as indicators of growth variability through the lifetime of these species. Before this experiment, bands were observed in eyestalks of snow crab (C. opilio), which is a congener of the southern Tanner crab (Kilada et al., 2012). We evaluated the mesocardiac of the southern Tanner crab because of the possibility that this structure may be retained through ecdysis (Kilada et al., 2012; Leland et al., 2015; but also see Vatcher et al., 2015). To our knowledge, description of growth bands in red king crabs is a first for the family Lithodidae. The appearance of bands in spot shrimp was very similar to that observed in the eyestalks of a congener, the northern shrimp ( $P$. borealis) (Kilada et al., 2012). Finally, most notably for the red king crab, a high proportion of the structures evaluated for growth bands were damaged during embedding or preparing thin sections. Structures were, by necessity, shipped dry before they were embedded in resin, and this condition likely contributed to their fragility and high fracture rate during the embedding and sectioning processes. Embedding structures before shipping could effectively mitigate this problem.

The absence of the basal region of the mesocardiac (where band patterns are observed in thin sections) in exuviae of southern Tanner and red king crabs indicated that this portion of the ossicle was either retained or replaced within 1 week after molting (Fig. 5, A and C). Recently it has been hypothesized that the endocuticle region of the pterocardiac and mesocardiac ossicles is retained through molting (Kilada et al., 2012; Leland et al., 2015). Calcein marks in the endocuticle were visible after several molts and portions of the ossicles were absent in the exuviae of lobster and crayfish species. However, for the blue crab, histological characterization of the cuticular layers of the dorsal ossicle (dorsomedial tooth) indicated that the dorsal cuticle (Roer and Dillaman, 1984), like the endocuticle, is resorbed during the premolt stage and resynthesized during the postmolt stage (Vatcher et al., 2015). As with brachyuran crabs (Brösing, 2014), the gastric teeth differed 


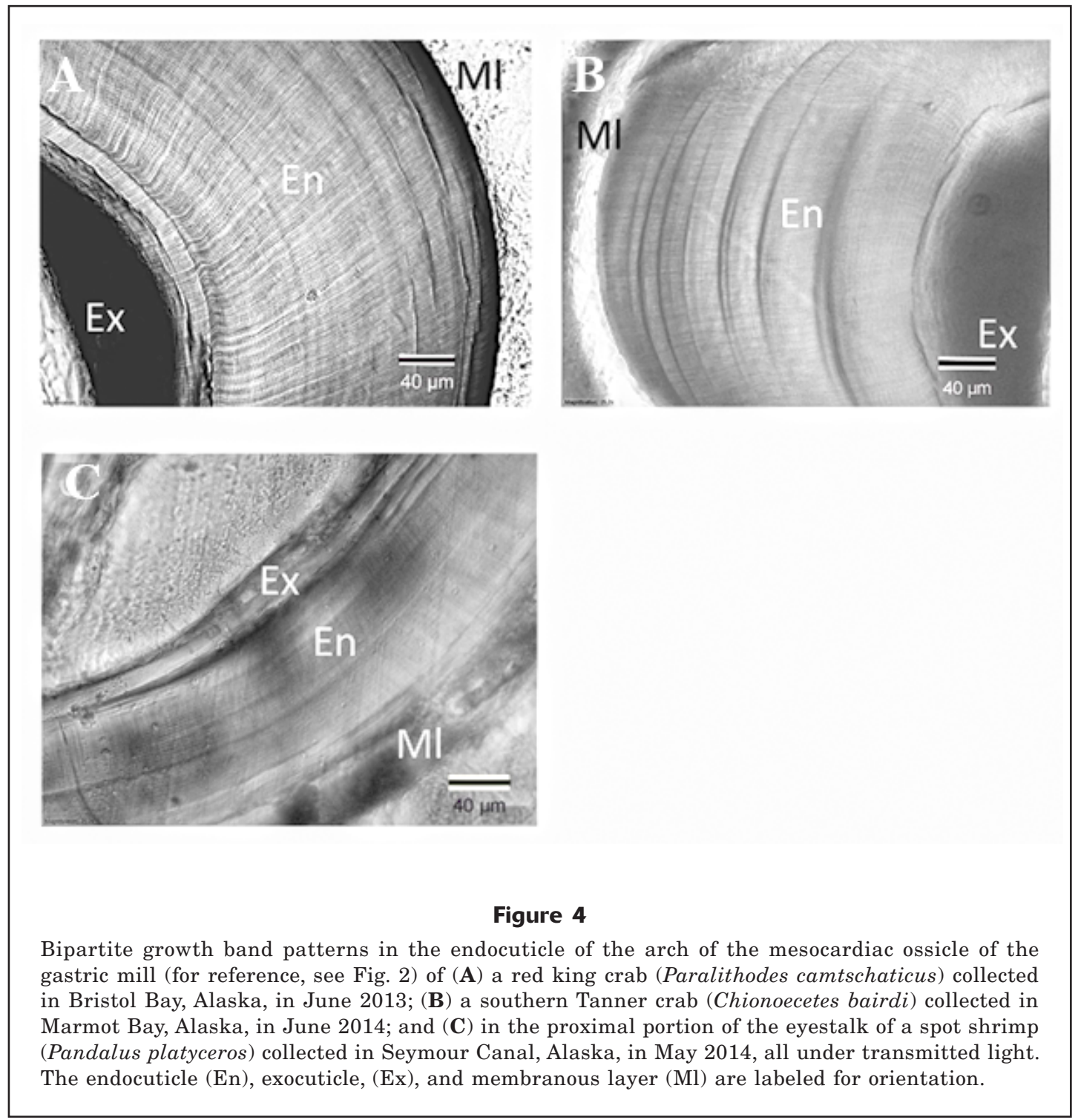

in biomineralization from other portions of the gastric mill (Vatcher et al., 2015) and remained in the exuviae of both crab species examined in this study.

Our results are an initial step toward developing and further evaluating growth bands as a possible indicator of age for commercially valuable crustaceans in Alaska. Key areas for further research include evaluations of variability (precision) in band count and clarity among the primary ossicles (pterocardiac, zygocardiac, and mesocardiac) of the gastric mill (Leland et al., 2011; Leland et al., 2015; Sheridan et al., 2015), innovation in preparation techniques for thin sections (Sheridan et al., 2015), definitions of criteria for identifying bands (e.g., Leland et al. 2015), determination of the fate (retention or replacement) of the endocuticle during molting (Vatcher et al., 2015), and corroboration of band counts with current understanding of species- specific growth, life history, and longevity based on indirect methods. Ultimately, hypotheses should also be developed regarding the mechanism by which growth bands are formed and retained in structures that are molted (shrimp eyestalk) or possibly retained (e.g., gastric mill ossicles) (Kilada et al., 2012; Leland et al., 2015; Vatcher et al., 2015).

Rigorous validation of bands as indices of age will also be necessary before their application in stock assessment and fisheries management (Beamish and McFarlane, 1983; Campana, 2001; Leland et al., 2011). Validation techniques potentially applicable to the species investigated in this study include the use of autofluorescent stains and the use of specimens with known ages. Autofluorescent stains, such as calcein, can create discrete marks in calcified hard parts that can be used to examine band deposition with 


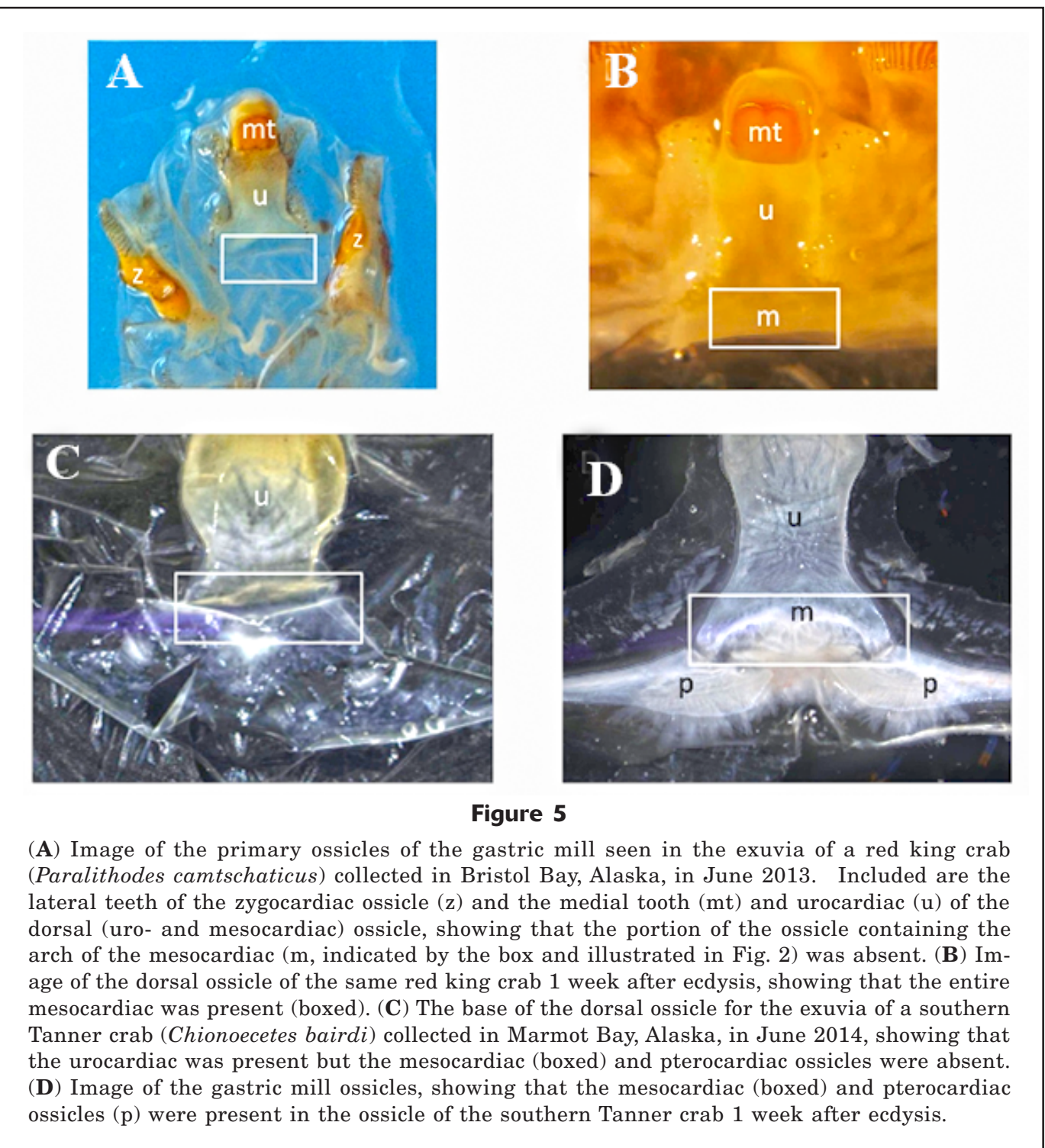

elapsed time after marking (Kilada et al., 2012; Leland et al., 2015). Further, determining band counts for crustaceans for which ages are known (e.g., animals reared in captivity) will be necessary to further understand dynamics of band formation (Leland et al., 2015).

\section{Acknowledgments}

This project was funded by the Alaska Department of Fish and Game. Thanks are extended to C. Siddon and D. Pengilly of the Alaska Department of Fish and Game for their support and to D. Oxman for an earlier review of this manuscript. Three anonymous reviewers contributed to significant improvement of the manuscript through review of a previous draft. This short contribution is professional publication number PP-280 of the Alaska Department of Fish and Game.

\section{Literature cited}

Abele, D., T. Brey, and E. Philipp.

2009. Bivalve models of aging and the determination of molluscan lifespans. Exp. Gerontol. 44:307-315. Article

Beamish, R. J., and G. A. McFarlane.

1983. The forgotten requirement for age validation in fisheries biology. Trans. Am. Fish. Soc. 112:735-743. Article Brösing, A.

2014. Foregut structures of freshly moutled exuviae from Maja crispate, Cancer pagurus and Pseudosesarma moeschi (Decapoda: Brachyura). J. Nat. Hist. 48:543-555. Article 
Caddy, J. F.

1986. Modelling stock-recruitment processes in Crustacea: some practical and theoretical perspectives. Can. J. Fish. Aquat. Sci. 43:2330-2344. Article

Campana, S. E.

2001. Accuracy, precision, and quality control in age determination, including a review of the use and abuse of age validation methods. J. Fish Biol. 59:197-242. Article

Donaldson, W. E., and S. C. Byersdorfer.

2005. Biological field techniques for lithodid crabs. Alaska Sea Grant College Program, AK-SG-05-03, 82 p. Univ. Alaska, Fairbanks. AK.

Evans, N. and A. Krajian.

1930. New method of decalcification. Arch. Path. 10:447.

Hartnoll, R. G.

2001. Growth in Crustacea-twenty years on. In Advances in decapod crustacean research: proceedings in the $7^{\text {th }}$ colloquium Crustacea Decapoda Mediterranea; Lisbon, Portugal, 6-9 September 1999 (J. P. M. Paula, A. A. V. Flores, and C. H. J. M. Fransen, eds.), p. 111122. Springer Science+Business Media, Dordrecht, Netherlands.

Jadamec, L. S., W. E. Donaldson, and P. Cullenberg.

1999. Biological field techniques for Chionoecetes crabs. Alaska Sea Grant College Program AK-SG-99-02, 80 p. Univ. Alaska, Fairbanks, AK.

Jensen, M.

1969. Age determination of echinoids. Sarsia 37:41-44. Article

Kilada, R., and E. Acuña.

2015. Direct age determination by growth band counts of three commercially important crustacean species in Chile. Fish. Res. 170:134-143. Article

Kilada, R., and N. K. Ibrahim.

2016. Preliminary investigation of direct age determination using band counts in the gastric mill of the blue swimmer crab (Portunus pelagicus Linneus, 1758) in two salt-water lakes in the eastern Mediterranean. J. Crust. Biol. 36:119-128. Article

Kilada, R. W., D. Roddick, and K. Mombourquette.

2007. Age determination, validation, growth and minimum size of sexual maturity of the greenland smoothcockle (Serripes groenlandicus, Bruguiere, 1789) in eastern Canada. J. Shellfish Res. 26:443-450. Article

Kilada, R., B. Sainte-Marie, R. Rochette, N. Davis, C. Vanier, and S. Campana.

2012. Direct determination of age in shrimps, crabs, and lobsters. Can. J. Fish. Aquat. Sci. 69:1728-1733. Article
Kilada, R., A.-L. Agnalt,, N. H. Arboe, S. Bjarnason, A. Burmeister, E. Farestveit, Ó. S. Gíslason, A. Guðlaugsdóttir, D. Guðmundsdóttir, J. P. Jónasson, et al.

2015. Feasibility of using growth band counts in age determination of four crustacean species in the Northern Atlantic. J. Crust. Biol. 35:499-503. Article

Krafft, B. A., M. Kvalsund, G. Søvik, E. Farestveit, and A.-L. Agnalt.

2016. Detection of growth zones in the eyestalk of the Antarctic krill Euphausia superba (Dana, 1852) (Euphausiacea). J. Crust. Biol. 36:267-273. Article

Leland, J. C., J. Coughran, and D. J. Bucher.

2011. A preliminary investigation into the potential value of gastric mills for ageing crustaceans. In New frontiers in crustacean biology: proceedings of the TCS summer meeting, Tokyo, 20-24 September 2009. Crustacean Monographs 15 (A. Asakura, ed.), p. 57-68. Article

Leland, J. C., D. J. Bucher, and J. Coughran

2015. Direct age determination of a subtropical freshwater crayfish (redclaw, cherax quadricarinatus) using ossicular growth marks. PLoS ONE 10(8):e0134966. Article

Pinchuk, A. I., H. R. Harvey, and G. L. Eckert.

2016. Development of biochemical measures of age in the Alaskan red king crab Paralithodes camtschaticus (Anomura): validation, refinement and initial assessment. Fish. Res. 183:92-98. Article

Quinn, T. J., II, and R. B. Deriso.

1999. Quantitative fish dynamics, 560 p. Oxford Univ. Press Inc., New York.

Roer, R., and R. Dillaman.

1984. The structure and calcification of the crustacean cuticle. Am. Zool. 24:893-909. Article

Sheridan, M., R. Officer, I. O'Connor, and C. Lordan.

2015. Investigating the feasibility of using growth increments for age determination of Norway lobster (Nephrops norvegicus) and brown crab (Cancer pagurus). J. Crust. Biol. 35:495-498. Article

Vatcher, H. E., R. D. Roer, and R. M. Dillaman.

2015. Structure, molting, and mineralization of the dorsal ossicle complex in the gastric mill of the blue crab, Callinectes sapidus. J. Morphol. 276:1358-1367. Article

Vogt, G.

2012. Ageing and longevity in the Decapoda (Crustacea): a review. Zool. Anz. 251: 1-25. Article

Zheng, J., M. C. Murphy, and G. H. Kruse.

1995. A length-based population model and stock-recruitment relationships for red king crab, Paralithodes camtschaticus, in Bristol Bay, Alaska. Can. J. Fish. Aquat. Sci. 52:1129-1246. Article 